\title{
Adsorption Kinetics of Copper by Biochars
}

\author{
Huiying Guo ${ }^{1,}$, Fang Yang ${ }^{1, b}$, Zhengqi Cheng ${ }^{1, c}$ and Yanzhi Yin ${ }^{2, d^{*}}$ \\ ${ }^{1}$ Faculty of Environmental Science and Engineering, Kunming University of Science and \\ Technology, Kunming, China \\ ${ }^{2}$ Wuhan Juzheng Environmental Science and Technology co., LTD, Wuhan, China \\ aguohuiying1990@126.coml, b1205726293@qq.com, 'chengzhengqi1990@foxmail.com, \\ dhelen75950@163.com
}

Keywords: biochars; Cu(II); sorption; peanut shells

Abstract. At present, the heavy metal pollution has become one of serious environmental problems which has drawn the great attention to scientists. Biochar has great sorption capacity to heavy metals. It has become one of hotspots research of soil science and environmental science because of its huge application prospect in agriculture and environment. In this paper, biochars were derived from peanut shells at different pyrolysis temperatures and limited-air condition. The elemental compositions of biochars were characterized. The results showed that the concentrations of $\mathrm{C}$ increased with increasing temperature as a result of combustion and volatilization; while $\mathrm{H}, \mathrm{O}$ decreased. The biochars showed appreciable capability of adsorption for copper from aqueous solution. The experimental data indicated that the sorption capacity of $\mathrm{Cu}$ (II) on the biochars increased by the increment of charring temperature, and decreased by the increment of charring time. It might be that biochar has aromatic ring structure after being charred.

\section{Introduction}

Copper $(\mathrm{Cu})$ is an essential micro-nutrient needed by human beings, animals and plants at low levels, while it is toxic beyond certain limits and can cause serious environmental and public health concerns. $\mathrm{Cu}$ mining and smelting produces large amount of acid drainage in China and worldwide, and has lead to pollution of river water by $\mathrm{Cu}$ and other heavy metals[1,2]. Irrigation using such water has resulted in accumulation of heavy metals in soil and their transport from soils to food and hence to the biosphere[3,4].

Biochar is a fine-grained and porous substance, similar in appearance to charcoal that is produced by pyrolysis of biomass under oxygen-limited conditions. In recent years, biochar has received considerable interest as a large-scale soil amendment to improve soil fertility, crop production, and nutrient retention and to serve as a recalcitrant carbon stock[5-7]. Biochar has a relatively structured carbon matrix with high degree of porosity and extensive surface area, suggesting that it may act as a surface sorbent which is similar in some aspects of activated carbon and thereby play an important role in controlling contaminants in the environment. Much work has been done on plant-residue or agricultural wastes derived biochar for sorbing organic pollutants[8-10].

While biochars from wood/bark[11], dairy manure[12] and biochars prepared from hydrothermal liquefaction of pinewood and rice husk[13] have been shown to sorb significant amounts of heavy metals (such as As, $\mathrm{Cd}$ and $\mathrm{Ni}$ ), there is very limited research on the effects of biochars derived from peanut shells on $\mathrm{Cu}$ (II) adsorption processes. Heavy metal pollutants such as $\mathrm{Cu}$ (II) often coexist in contaminated urban areas, and their mobility is of global concern[14]. The objective of this study was to investigate the sorption ability of $\mathrm{Cu}$ (II) by biochars derived from peanut shells at different pyrolysis temperatures and limited-air condition in aqueous solution.

\section{Experimental}

Preparation of biochars. The straws of peanut were air-dried at room temperature and ground to pass a $0.154 \mathrm{~mm}$ sieve, which were as raw biomass material. The straws of peanut were heated at different 
pyrolysis temperature to obtain biochars under hypoxic conditions, respectively $200^{\circ} \mathrm{C}, 400^{\circ} \mathrm{C}, 700^{\circ} \mathrm{C}$. One biochar was made from a mix of peanut shells heated in a muffle furnace at three different temperature for $2 \mathrm{~h}$ and $4 \mathrm{~h}$ (designated as M22, M42, M72, M24, M44, M74). The other biochar was produced from peanut shells heated via microwave under the same temperature and while (Marked W22, W42, W72, W24, W44, W74). For the comparison, the original manure dried at the temperature of $105^{\circ} \mathrm{C}$ (referred to as $\mathrm{B} 0$ ) was included.

Characterization of biochars. The biochars produced from the peanut shell samples were characterized used elemental analyzer (Elementar MicroCube), thermogravimetry (TG), and Fourier Transform Infrared Spectroscopy (Varian 640 - IR). The basic elements (C, H, O, N, S) analyses were conducted on elemental analyser. Thermogravimetry was conducted using a computer-controlled thermogravimetric analyser. The biochar samples were heated from 25 to $1000{ }^{\circ} \mathrm{C}$ at a rate of $20{ }^{\circ} \mathrm{C}$ per min. Weight loss attributed to mineral reactions that produced volatile reaction products $\left(\mathrm{H}_{2} \mathrm{O}\right.$, $\mathrm{CO}_{2}$ ) at specified temperature ranges. Quantitative mass loss was used to determine organic matter loss via combustion and calcite $\left(\mathrm{CaCO}_{3}\right)$ mass percent based on the stoichiometry of its decomposition reaction. In addition, the samples scanned from 4000 to $400 \mathrm{~cm}^{-1}$ at a resolution of $8 \mathrm{~cm}^{-1}$ and mirror velocity of $0.48 \mathrm{~cm} / \mathrm{s}$ during the FTIR analysis.

Adsorption kinetics of copper to biochars. The purpose was to determine potential of biochars for sorption of heavy metals for aqueous solutions, $\mathrm{Cu}$ was chosen as model heavy metal contaminant, respectively. In our study, the $\mathrm{Cu}\left(\mathrm{NO}_{3}\right)_{2}$ solution(concentrations of $5 \mathrm{mgL}^{-1}$ ) were selected as adsorbates, and the solid-liquid ratio was 1: $4 \mathrm{mg} / \mathrm{mL}$. The sorption experiment was conducted in $120 \mathrm{~mL}$ brown bottle by mixing 30mg of biochars (M22, M42, M72, M24, M44, M74, W22, W42, W72, W24, W44, W74 and B0) with $120 \mathrm{~mL}$ solution containing $25 \mathrm{mgL}^{-1} \mathrm{Cu}\left(\mathrm{NO}^{3}\right)^{2}$ and 1168.8 $\mathrm{mgL}^{-1}$ background liquid of $\mathrm{NaCl}$, and the $\mathrm{pH}$ was 6.0 . Then the mixture was shaken at a shaking table at constant temperature $\left(25^{\circ} \mathrm{C}\right)$, respectively being shaken for $0.25,0.5,1,2,3,4,6,8,9,19,27,43 \mathrm{~h}$ and samples were removed at each time point simultaneously, solid and liquid phases were separated by centrifugation at $2000 \mathrm{rpm}$ for $5 \mathrm{~min}$. Each biochar sample at different temperatures and different time points was taken two parallel samples, $0.5 \mathrm{~mL}$ of the supernatant was extiracted at $4 \mathrm{~mL}$ vial each time. The supernatant was analysed for $\mathrm{Cu}(\mathrm{II})$ concentrations using atomic absorption spectrophotometer. Calculation of sorption of $\mathrm{Cu}(\mathrm{II})$ was based on the difference between initial and final solution concentrations.

\section{Results and discussion}

Elemental analysis of biochars. 13 different kinds of biochars were analyzed by elemental analyzer, the results are shown in Table 1 . The measured elements include $\mathrm{C} \%, \mathrm{~N} \%, \mathrm{H} \%, \mathrm{~S} \%, \mathrm{O} \%$. As presented in Table 1, under the same pyrolysis method and the same charring time, The $\mathrm{C}, \mathrm{S}$ contents of biochars increased with increasing temperature, $\mathrm{H}, \mathrm{O}$ contents decreased as temperature increased. However, under different charring time, $\mathrm{C}$ content increased by the increment of charring time, on the contrary, $\mathrm{H}, \mathrm{O}, \mathrm{N}$ contents were reduced. In addition, biochars were produced under the same temperature and the same charring time by using different pyrolysis methods, $\mathrm{C}, \mathrm{H}$ contents of biochars which were heated by muffle furnace were slightly higher than that derived via microwave, conversely, $\mathrm{O}, \mathrm{N}$ contents were slightly lower.

$(\mathrm{N}+\mathrm{O}) / \mathrm{C}, \mathrm{O} / \mathrm{C}$ and $\mathrm{H} / \mathrm{C}$, respectively, reflected the polarity[15], hydrophobicity and chain structure of matter. The polarity and hydrophobicity of biochars, which were derived from peanut shells were reduced with increasing pyrolysis temperature, similarly, $\mathrm{H}$ / C atomic ratio decreased with pyrolysis temperature increased (Table 1). Other studies showed that biochars formed a highly tight aromatic structure when $\mathrm{H} / \mathrm{C}$ ratio was less than 0.3 , while the $\mathrm{H} / \mathrm{C}$ ratio was larger than 0.7 represents that aromatic ring structure of biochars was not tight enough or the aliphatic chain was as the main structure[16]. In our study, $\mathrm{H} / \mathrm{C}$ ratios of biochars was less than 0.3 , this phenomenon indicated that the formation of more aromatic ring structure resulted from carbonization, thereby biochars became very compact[17]. 
Table.1 Concentrations of the concerned elements of the original sample and peanut shells-derived biochar produced at temperatures from 200 to $700{ }^{\circ} \mathrm{C}$.

\begin{tabular}{|c|c|c|c|c|c|c|c|c|c|c|}
\hline \multirow[t]{2}{*}{$\begin{array}{c}\text { Sample } \\
\mathrm{s}\end{array}$} & \multirow{2}{*}{$\begin{array}{l}\text { Time } \\
\text { (h) }\end{array}$} & \multirow{2}{*}{$\begin{array}{c}\text { Temperatur } \\
\text { e } \\
\left({ }^{\circ} \mathrm{C}\right)\end{array}$} & \multicolumn{5}{|c|}{ Elemental compositions ( $\%$ ) } & \multicolumn{3}{|c|}{ Atomic ratio } \\
\hline & & & $\mathrm{C}$ & $\mathrm{H}$ & $\mathrm{O}$ & $\mathrm{N}$ & $\mathrm{S}$ & $(\mathrm{N}+\mathrm{O}) / \mathrm{C}$ & $\mathrm{O} / \mathrm{C}$ & $\mathrm{H} / \mathrm{C}$ \\
\hline B0 & - & - & 44.98 & 5.53 & 40.50 & 1.26 & 0.07 & 0.93 & 0.90 & 0.12 \\
\hline M22 & 2 & 200 & 48.90 & 5.58 & 38.17 & 1.25 & 0.29 & 0.81 & 0.78 & 0.11 \\
\hline M42 & 2 & 400 & 62.76 & 3.13 & 14.63 & 1.69 & 0.31 & 0.26 & 0.23 & 0.05 \\
\hline M72 & 2 & 700 & 66.09 & 1.32 & 9.19 & 0.91 & 0.21 & 0.15 & 0.14 & 0.02 \\
\hline M24 & 4 & 200 & 49.37 & 5.00 & 35.97 & 1.13 & 0.11 & 0.75 & 0.73 & 0.10 \\
\hline M44 & 4 & 400 & 67.07 & 3.23 & 13.56 & 1.51 & 0.20 & 0.22 & 0.20 & 0.05 \\
\hline M74 & 4 & 700 & 63.12 & 1.27 & 9.91 & 0.93 & 0.27 & 0.17 & 0.16 & 0.02 \\
\hline W22 & 2 & 200 & 47.16 & 5.13 & 38.19 & 1.22 & 0.11 & 0.84 & 0.81 & 0.11 \\
\hline W42 & 2 & 400 & 59.12 & 3.08 & 22.86 & 1.94 & 0.22 & 0.42 & 0.39 & 0.05 \\
\hline W72 & 2 & 700 & 60.87 & 1.66 & 11.60 & 1.41 & 0.22 & 0.21 & 0.19 & 0.03 \\
\hline W24 & 4 & 200 & 48.05 & 5.04 & 37.46 & 1.22 & 0.11 & 0.80 & 0.78 & 0.10 \\
\hline W44 & 4 & 400 & 63.25 & 3.14 & 23.05 & 1.77 & 0.27 & 0.39 & 0.36 & 0.05 \\
\hline W74 & 4 & 700 & 81.17 & 1.45 & 8.42 & 1.21 & 0.19 & 0.12 & 0.10 & 0.02 \\
\hline
\end{tabular}

TG analysis. This study was designed to investigate the mass loss with increasing temperature of biochars, which derived from peanut shells and analyzed the composition and the reasons for the loss by thermal gravimetric analysis. As presented in Fig. 1, the mass loss resulted from the combustion or oxidation with increasing charring temperature. The mass and ash were remained stablely while the sample ran out of fuel. Furthermore, mass loss at temperature up to $80{ }^{\circ} \mathrm{C}$ (Fig. 1) resulted possibly from sorped water volatilization. The maximum mass loss for both original peanut shell sample and M22 were between 250 and $500{ }^{\circ} \mathrm{C}$, while between 300 and $500{ }^{\circ} \mathrm{C}$ for M42 and between 450 and 550 ${ }^{\circ} \mathrm{C}$ for M72. In general, in all biochars, more than $90 \%$ mass loss of volatilization occurred between 250 and $500{ }^{\circ} \mathrm{C}$.

Both original peanut shell sample and M22 formed a large endothermic peak (Fig. 1), these two peaks were contained in the range of $300^{\circ} \mathrm{C}$ to $500{ }^{\circ} \mathrm{C}$, previous literatures pointed that the main mass loss was organic matter in this process. While M42 and M72 formed the other two endothermic peaks at $400^{\circ} \mathrm{C}$ and $550{ }^{\circ} \mathrm{C}$, respectively. At the same time, mass loss on ignition temperature of carbon increased, this phenomenon probably due to the formation of organic mineral complex during the pyrolysis process. However, when the temperature rised to above $500^{\circ} \mathrm{C}$, carbon which in organic mineral complex was eventually lost via pyrolysis. 

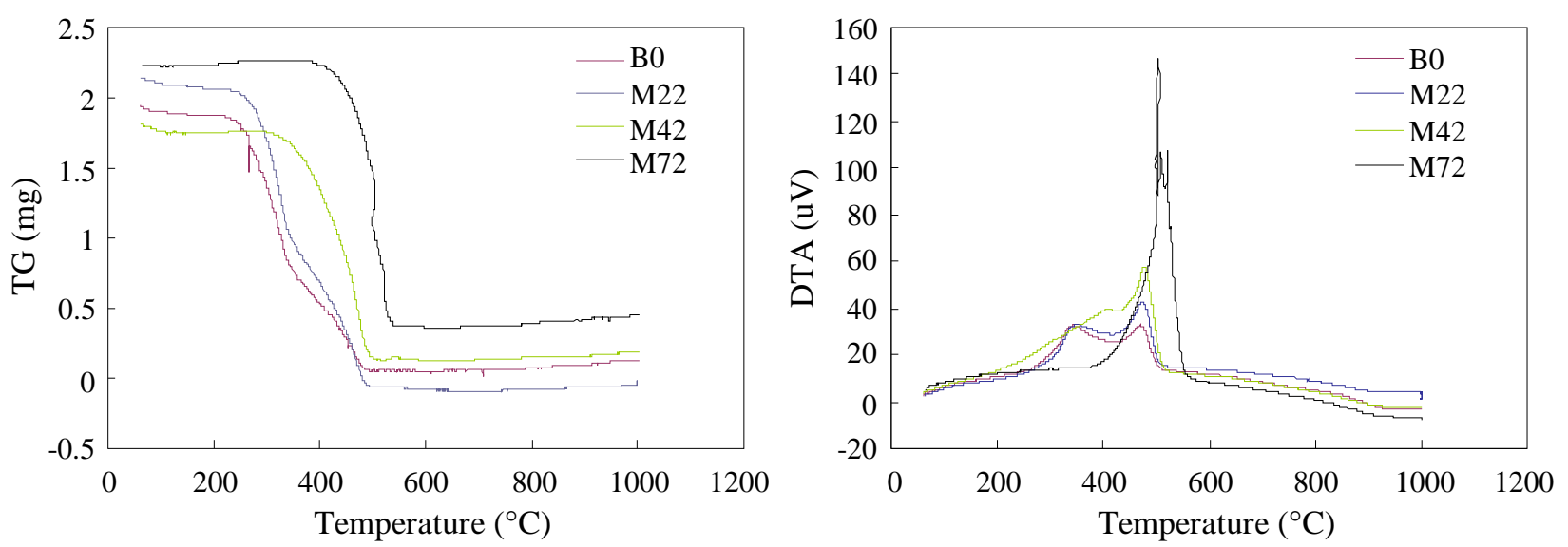

Fig. 1 TG and DTA analysis of the peanut shell $\left(105^{\circ} \mathrm{C}\right)$ and biochar (M22-M72) prepared at temperatures from $200{ }^{\circ} \mathrm{C}$ to $700{ }^{\circ} \mathrm{C}$.

FTIR analysis. Differences in infrared spectra reflected water loss, organic matter combustion, and the concentration of mineral components that resulted from those heat-induced mass losses. The spectrum of original sample and biochars heated by muffle furnace for $2 \mathrm{~h}$ and $4 \mathrm{~h}$ were characterized by the organic function groups, showing a band from $-\mathrm{OH}$ stretching $\left(3436 \mathrm{~cm}^{-1}\right)[18], \mathrm{CH} 2$ (2851 and $\left.2927 \mathrm{~cm}^{-1}\right)[19,20]$ in biopolymers, $\mathrm{C}=\mathrm{O}$ stretching of aromatic rings $\left(1623 \mathrm{~cm}^{-1}\right)$ (Fig. $2 \mathrm{~A}$ and B). These bands expectedly decreased with increasing pyrolysis temperature. The band of $-\mathrm{OH}$ stretching $\left(3436 \mathrm{~cm}^{-1}\right)$ significantly reduced in the range of $200^{\circ} \mathrm{C}$ to $400^{\circ} \mathrm{C}$, and it almost disappeared when temperature reached $400^{\circ} \mathrm{C}$ or $700^{\circ} \mathrm{C}$. This phenomenon caused the dehydration and dehydroxylation of biochars in the carbonization process, hence occurring a substantial loss of hydroxyl and the absorption peak reduced significantly. Furthermore, The band of $\mathrm{CH} 2$ stretching $\left(2851 \mathrm{~cm}^{-1}\right.$ and 2927 $\mathrm{cm}^{-1}$ ) weakened with the increase of temperature, which means that the contents of methyl and methylene groups of biochars decreased as the preparation increasing temperature.

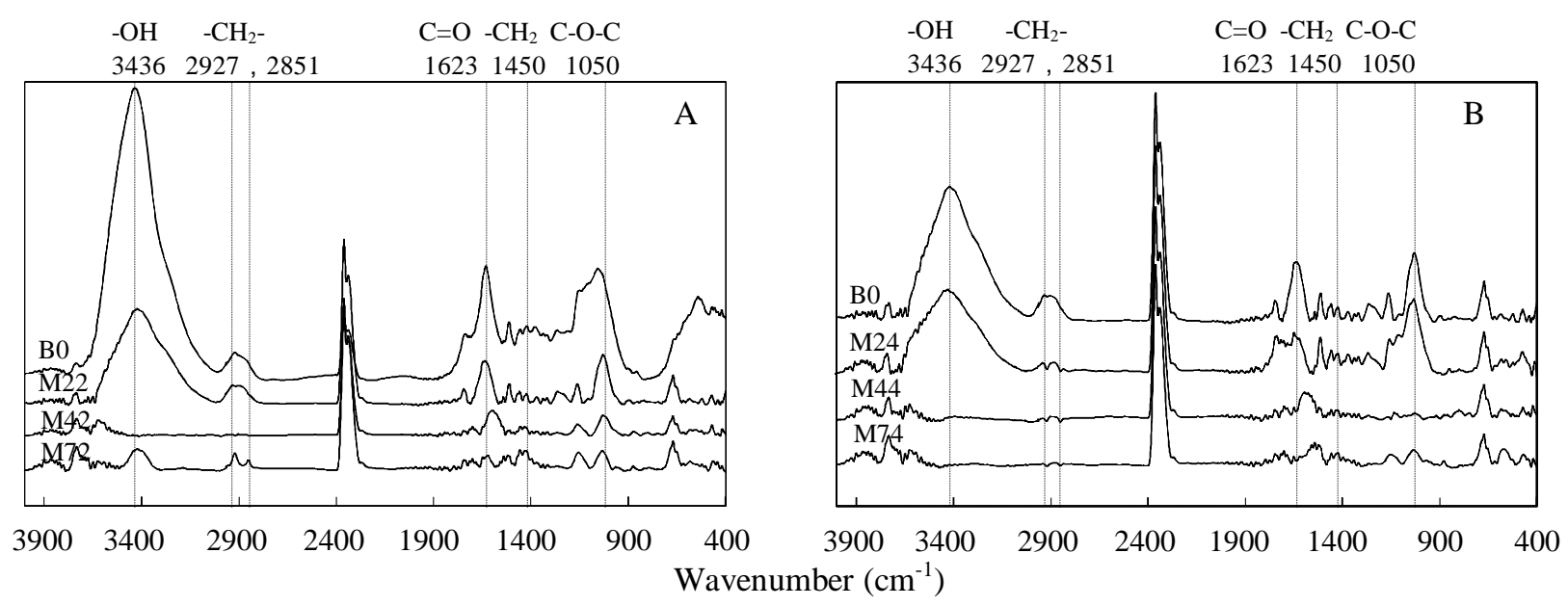

Fig. 2 FT-IR spectra of biochars prepared at different temperatures (A for $2 \mathrm{~h}, \mathrm{~B}$ for $4 \mathrm{~h}$ ) by muffle furnace.

Copper sorption by biochar. Experimental results showed that sorption capacity of both two biochars to copper ions, which produced by using a muffle furnace or a microwave-fired increased with increasing pyrolysis temperature at the same concentration of $\mathrm{Cu}$ (II) solution and the same charring time. As we known, there are many oxygen and nitrogen functional groups on the surface of biochar, all these functional groups readily complexed with metal ions, thus metal ions adsorbed on biochar by surface complexation. Previous studies showed that the atomic ratio $\mathrm{H} / \mathrm{C}$ content of biochar reduced with the pyrolysis temperature (Table 1), which means that those biochars formed a greater amount of aromatic rings, which were multi-electron aromatic ring structure, cation $-\pi$ action ensued between the aromatic rings and the metal ions[17], thereby enhancing the adsorption of $\mathrm{Cu}$ (II) by biochars. Besides, the $\mathrm{Cu}$ (II) adsorption amount of biochars which were heated at $200^{\circ} \mathrm{C}$ and $400^{\circ} \mathrm{C}$ was less than raw peanut shells. Studies have shown that components of peanut shells were complex, which contained catechins, gallic acid, phloroglucinol and other polyphenol and minerals, fats and lots of 
cellulose-based substances. Hence, in the pyrolysis process, the carbonization of biomass was largely dependent on the degree of temperature. However, in both $200^{\circ} \mathrm{C}$ and $400^{\circ} \mathrm{C}$ such low temperature, carbonization of biomass was not completed, comparing to the original biomass of peanut shells, $\mathrm{O}, \mathrm{H}$ and $\mathrm{N}$ contents were both reduced (Table 1). Correspondingly, the oxygen and nitrogen functional groups would reduce, thus decreasing the adsorption of metal ions on the biochar. That's why the adsorption amount of $\mathrm{Cu}$ (II) on the biochars heated in both degree of temperature was less than the original biomass of peanut shells.

In addition, under the same pyrolysis temperature, the $\mathrm{Cu}(\mathrm{II})$ adsorption dosage of all these biochars decreased by the increment of charring time. The case was caused by the specific factor that $-\mathrm{OH}$, $-\mathrm{COOH}, \mathrm{C}=\mathrm{O}, \mathrm{C}-\mathrm{O}-\mathrm{C}$ and other surface oxygen functional groups of biochars reacted with $\mathrm{Cu}$ (II) to combine into -O-Cu-. According to FTIR analysis (Fig. 3), the absorption peak intensity of the oxygen functional groups of biochars was reduced after being heated for $4 \mathrm{~h}$, which affected $-\mathrm{O}-\mathrm{Cu}-$ generation, thus reducing the amount of metal ions adsorbed on the biochar.
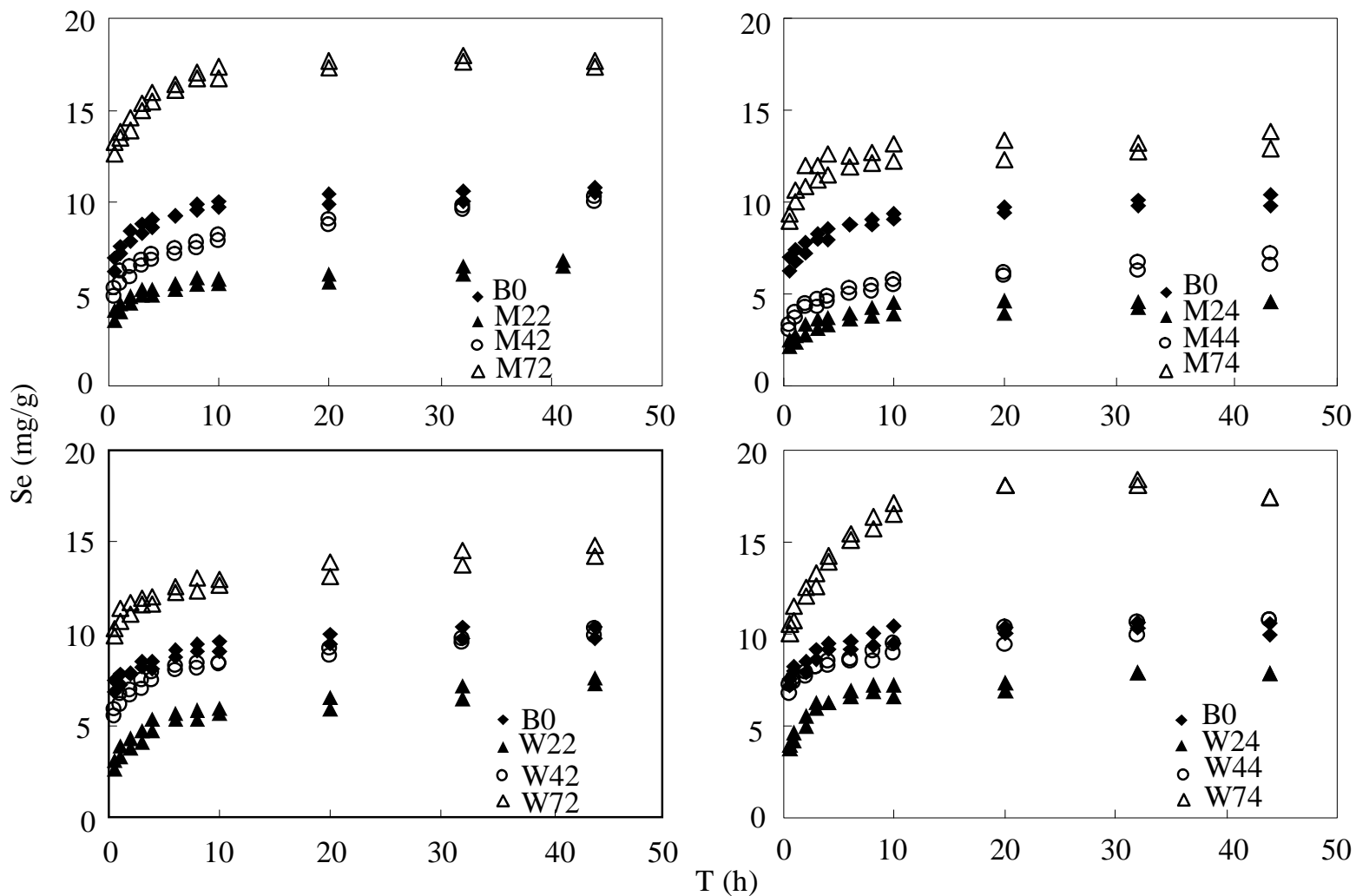

Fig.3 Adsorption kinetics curves of concentration of $5 \mathrm{mg} / \mathrm{L} \mathrm{Cu}(\mathrm{II})$ to biochars at different temperature

\section{Concluding remarks and environmental significance}

This study investigated that peanut shells can be efficiently converted into a biochar material with potential to serve as an amendment for remediation or agronomic purposes and the sorption capacity of biochar which derived from peanut shells to $\mathrm{Cu}$ (II) from aqueous solution was strong. Furthermore, the conversion temperature affects biochar properties, which affects biochar application. Heating at $\geq 200{ }^{\circ} \mathrm{C}$ in presence of air resulted in partial combustion of peanut shells, producing a large amount of mass loss and the $\mathrm{Cu}(\mathrm{II})$ adsorption amount of biochar increased with increasing preparation temperature and decreased by the increment of charring time. With the increasing pyrolysis temperature, forming a substantial amount of aromatic rings, cation $-\pi$ action ensued between the aromatic rings and the metal ions, thereby enhancing the adsorption of $\mathrm{Cu}$ (II) by biochars. Besides, heating for $\geq 4 \mathrm{~h}$ reduced the contents of surface oxygen functional groups, which affected $-\mathrm{O}-\mathrm{Cu}$ generation and reduced the amount of metal ions adsorbed on the biochar. Thus, biochar derived from peanut shells has potential to be an effective adsorbent for application in environmental remediation. 
To sum up, turning crop into biochar for remediation application shows promise as a means to solve disposal problem while creating new markets for crop.

\section{References}

[1] L. S. Balistrieri, R. R. Seal, N. M. Piatak, B. Paul, USA, Applied Geochemistry, 2007, 22, (5), 930-952.

[2] H. Y. Xiao, W. B. Zhou, F. P. Zeng, D. S. Wu, Environmental Earth Sciences, 2010, 59, (5), 1023-1031.

[3] S. Lee, Geoderma, 2006, 135, 26-37.

[4] H. Y. Liu, A. Probst, B. H. Liao, Science of the Total Environment, 2005, 339, (1-3), 153-166.

[5] D. A. Laird, Agronomy Journal, 2008, 100, (1), 178-181.

[6] J. Lehmann, J. Gaunt, M. Rondon, Mitigation and adaptation strategies for global change, 2006, $11,(2), 395-419$.

[7] D. Woolf, A review of the environmental implications. (2008)

[8] X. Wang, T. Sato, B. Xing, Environmental science \& technology, 2006, 40, (10), 3267-3272.

[9] X. Wang, B. Xing, Environmental science \& technology, 2007, 41, (24), 8342-8348.

[10] Y. Yang, G. Sheng, Environmental science \& technology, 2003, 37, (16), 3635-3639.

[11]D. Mohan, C. U. Pittman, M. Bricka, F. Smith, B. Yancey, J. Mohammad, P. H. Steele, M. F. Alexandre-Franco, V. Gomez-Serrano, H. Gong, Journal of Colloid and Interface Science, 2007, 310, (1), 57-73.

[12] X. Cao, L. Ma, B. Gao, W. Harris, Environmental Science \& Technology, 2009, 43, (9), 3285-3291.

[13]Z. Liu, F. S. Zhang, Journal of Hazardous Materials, 2009, 167, (1), 933-939.

[14] M. Uchimiya, I. M. Lima, K. Thomas Klasson, S. Chang, L. H. Wartelle, J. E. Rodgers, Journal of Agricultural and Food Chemistry, 2010, 58, (9), 5538-5544.

[15]B. Chen, Z. Chen, Chemosphere, 2009, 76, (1), 127-133.

[16]T. Kuhlbusch, P. Crutzen, Global Biogeochemical Cycles, 1995, 9, (4), 491-501.

[17]D. Wu, B. Pan, M. Wu, H. Peng, D. Zhang, B. Xing, Science of the Total Environment, 2012, 427, 247-252.

[18] J. Yu, N. Wang, X. Ma, Biomacromolecules, 2008, 9, (3), 1050-1057.

[19] A. S. Gunasekara, M. J. Simpson, B. S. Xing, Environmental Science \& Technology, 2003, 37 , (5), 852-858.

[20]B. Wen, J. J. Zhang, S. Z. Zhang, X. Q. Shan, S. U. Khan, B. Xing, Environmental Science \& Technology, 2007, 41, (9), 3165-3171. 